\title{
Auditory event-related potentials in children with benign epilepsy with centro-temporal spikes
}

\author{
David Tomé ${ }^{a, b, *}$, Mafalda Sampaio ${ }^{c}$, José Mendes-Ribeiro ${ }^{d}$, \\ Fernando Barbosa $^{\mathrm{b}}$, João Marques-Teixeira ${ }^{\mathrm{b}}$
}

\author{
a Laboratory of Audiology, Department of Audiology, School of Allied Health Sciences, Polytechnic Institute \\ of Porto, Portugal \\ ${ }^{\mathrm{b}}$ Laboratory of Neuropsychophysiology, Faculty of Psychology and Educational Sciences, University of \\ Porto, Portugal \\ c Serviço de Neuropediatria, Hospital de São João, Portugal \\ ' Serviço de Neurologia, Hospital de São João, Portugal
}

\section{KEYWORDS}

Benign rolandic

epilepsy;

$\mathrm{N} 1$;

$\mathrm{N} 2 \mathrm{~b}$;

MMN;

Auditory processing
Summary Benign focal epilepsy in childhood with centro-temporal spikes (BECTS) is one of the most common forms of idiopathic epilepsy, with onset from age 3 to 14 years. Although the prognosis for children with BECTS is excellent, some studies have revealed neuropsychological deficits in many domains, including language. Auditory event-related potentials (AERPs) reflect activation of different neuronal populations and are suggested to contribute to the evaluation of auditory discrimination (N1), attention allocation and phonological categorization (N2), and echoic memory (mismatch negativity - MMN). The scarce existing literature about this theme motivated the present study, which aims to investigate and document the existing AERP changes in a group of children with BECTS.

AERPs were recorded, during the day, to pure and vocal tones and in a conventional auditory oddball paradigm in five children with BECTS (aged 8-12; mean $=10$ years; male $=5$ ) and in six gender and age-matched controls. Results revealed high amplitude of AERPs for the group of children with BECTS with a slight latency delay more pronounced in fronto-central electrodes.

Children with BECTS may have abnormal central auditory processing, reflected by electrophysiological measures such as AERPs. In advance, AERPs seem a good tool to detect and reliably reveal cortical excitability in children with typical BECTS. 


\section{Introduction}

Benign epilepsy with rolandic or centro-temporal spikes (BECTS) is the most common form of idiopathic epilepsy in children, with age of seizure onset between 3 and 14 years, representing $8-23 \%$ of epilepsies under the age of 16 and is more common in boys than girls (Bernardina et al., 2005). It is defined as a truly benign partial idiopathic epilepsy, mainly because spontaneous recovery usually occurs before adolescence in absence of neurological and cognitive impairment, whether antiepileptic medication is started or not (Nicolai et al., 2007). However, several studies have questioned the benign nature of BECTS reporting neuropsychological deficits in many domains (Liasis et al., 2006; Myatchin et al., 2009). This seems to be related with the atypical form of BECTS, characterized by the presence of neurological deficits, continuous spike wave during sleep, atypical absences, speech delay, and intellectual deficits (Wong et al., 1985).

BECTS patients show scalp topography of synchronous discharges of the EEG with largest amplitudes over the temporal areas of both hemispheres and over frontocentral regions (Braga et al., 2000; Pan and Lüders, 2000). In addition, high amplitude of somatosensory evoked potentials has been reported reflecting enhancement of cortical excitability even during sleep (Ferri et al., 2000). This is consistent with other research on motor evoked potentials elicited by transcranial magnetic stimulation, that causes an increase in amplitude substantially above normal values in children with BECTS (Manganotti and Zanette, 2000; Skrandies and Dralle, 2004). However, literature is scarce concerning auditory processing reflected on electrophysiological measures such as auditory event-related potentials (AERPs). In this line of research, Liasis et al. (2006) reported that asymmetry of P85-120 and absence of mismatch negativity (MMN) during wake recordings may indicate abnormal processing of auditory information at a sensory level. The presence of structural abnormality indicated by imaging is not a predictor of ERPs abnormalities to visual and auditory modalities (Turkdogan et al., 2003). In a comprehensive study, Boatman et al. (2008) using behavioral and electrophysiological methods demonstrated speech recognition impairments in a group of children with BECTS reflecting dysfunction of nonprimary auditory cortex, with the presence of $N 100$ and $M M N$ to tones but the absence of $M M N$ to speech stimuli.

The ability to detect, discriminate and analyze auditory stimuli is essential for normal learning and development. AERPs provide objective measures of central auditory processing. These scalp recorded potentials reflect activation of different neuronal populations that are suggested to contribute to auditory discrimination (N1), attention allocation and phonological categorization (N2), automatic pre-attentive discrimination and perception, and echoic memory (MMN) (Näätänen, 1995; Liasis et al., 1999, 2001; Henkin et al., 2002).

The aim of the present study was to investigate and document putative changes in AERPs components (N1, N2b, and $M M N$ ) in a group of children with BECTS.

\section{Methods}

Five children (all male; $M=10.0$ years; $S D=1.87$; range 8-12) with clinical and electroencephalographic criteria for BECTS were included in the study and compared with a matched control group of 6 healthy children (all male; $M=11.3$ years; $S D=2.65$; range $7-14$ ).

All participants had normal hearing and vision, no ear malformation, and no neurological or mental deficits. Children from BECTS were seizure free for the last 3 months and no history of language regression with the onset of seizures. Medication and other clinical characteristics are shown in Table 1.

Based on parental report, all participants were enrolled in mainstream academic programs (BECTS group: $M=4$ years of education, $S D=1.87$; control group: $M=5.17$ years of education, $S D=2.48$ ). Both groups had one child left handed and the rest right handed.

The experimental procedures followed the tenets of the Declaration of Helsinki. It was approved by the local Ethics Committee from Hospital São João (CES - Comissão de Ética para a Saúde) and parents gave informed consent concerning their children's participation in the study.

During EEG recording $(512 \mathrm{~Hz}$ sampling and bandwidth $0.05 \mathrm{~Hz}-100 \mathrm{~Hz}$; 32 channel bio-amplifier Refa32, ANT Neuro, Netherlands) participants were presented with two active auditory oddball paradigms: a block of pure-tone stimuli (std: $1000 \mathrm{~Hz}$; dev: $1100 \mathrm{~Hz}$; created in Audacity software v2.0.0) and other of consonant-vowel (CV digitalized rate of $44,100 \mathrm{~Hz}$ with $175 \mathrm{~ms}$ duration, spoken by a male Portuguese voice; std:/ba/ $118 \mathrm{~Hz}$; dev:/pa/127 Hz, recorded with Nuendo sof tware v4.3.0) with a stimulus onset asynchrony (SOA) of $800 \mathrm{~ms}$, to a proximal sound level of $75 \mathrm{~dB}$ SPL. In both blocks (300 trials), standard stimuli comprised $80 \%$ of all trials, while deviant stimuli comprised $20 \%$. Recordings were obtained from: $\mathrm{Cz}, \mathrm{Fz}, \mathrm{Fpz}, \mathrm{M} 1, \mathrm{M} 2$ and $\mathrm{Oz}$ (ground), referenced to averaged ear lobes (A1 and A2). An electrode was attached above right eye to monitor the electrooculogram (EOG). Impedance between the electrodes and skin were kept below $10 \mathrm{k} \Omega$ at all sites. Stimuli were presented using Presentation ${ }^{\circledR}$ software (Neurobehavioral Systems, Inc.) via closed headphones while the participants where comfortably seated in an armchair and instructed to keep alert with eyes-open, passively listening to auditory stimuli and focused on a small cross in the center of a computer screen during recording. Preprocessing included band-pass filtering $(0.3-30 \mathrm{~Hz})$, entire sweep linear detrending and a baseline correction of individual epochs (60 ms).

The $M M N$ was determined from the $\mathrm{Fpz}, \mathrm{Fz}, \mathrm{Cz}, \mathrm{M} 1$ and M2 electrodes, by computing difference waves, i.e. by subtracting the average standard-stimulus response from the average deviant-stimulus response for each electrode and subject. The N1 and N2b were identified as the two largest negative peaks occurring between 100 and $300 \mathrm{~ms}$.

\section{Results}

The N1 and N2b auditory ERP components were present in all participants for both pure-tones and CV conditions. 
Table 1 Individual characteristics of the clinical sample.

\begin{tabular}{|c|c|c|c|c|c|c|c|c|}
\hline Patients & $\begin{array}{l}\text { Age } \\
\text { (years) }\end{array}$ & $\begin{array}{l}\text { Age at } \\
\text { seizure } \\
\text { onset } \\
\text { (years) }\end{array}$ & $\begin{array}{l}\text { Handedness } \\
\text { index }(\%)\end{array}$ & $\begin{array}{l}\text { Laterality of } \\
\text { epileptic } \\
\text { focus }\end{array}$ & Lesion & $\begin{array}{l}\text { AEDs } \\
\text { (mg/kg/day) }\end{array}$ & $\begin{array}{l}\text { Academic } \\
\text { skills }\end{array}$ & $\begin{array}{l}\text { Systemic } \\
\text { disease }\end{array}$ \\
\hline 1 & 8 & 3 & -76.7 & $\mathrm{RCP}$ & None & CBZ (18) & Excellent & No \\
\hline 2 & 12 & $\begin{array}{l}\text { No } \\
\text { seizures }\end{array}$ & 93.3 & $\mathrm{BCT}$ & $\begin{array}{l}\text { MRI not } \\
\text { performed }\end{array}$ & No & Good & No \\
\hline 3 & 12 & 7 & 80.0 & $\mathrm{BCT}$ & $\begin{array}{l}\text { MRI not } \\
\text { performed }\end{array}$ & VPA (20) & $\begin{array}{l}\text { Slight } \\
\text { learning } \\
\text { difficulties } \\
\text { (IQ 74) }\end{array}$ & No \\
\hline 4 & 9 & 5 & 66.7 & LCT & $\begin{array}{l}\text { MRI not } \\
\text { performed }\end{array}$ & VPA (20) & Good & No \\
\hline 5 & 9 & $\begin{array}{l}\text { No } \\
\text { seizures }\end{array}$ & 45.0 & $\mathrm{BCT}$ & None & No & Good & $\begin{array}{l}\text { CPT II } \\
\text { deficiency }\end{array}$ \\
\hline
\end{tabular}

M, male; AEDs, antiepileptic drugs; VPA, valproic acid; CBZ, carbamazepine; CPT II, carnitine palmitoyltransferase. BCT, bilateral centrotemporal; LCT, left centro-temporal; RCP, right centro-parietal.

Statistically significant results were obtained with nonparametric tests (Wilcoxon - two independent samples), for $\alpha=0.1$.

\section{Pure-tones}

Mild reduced amplitudes of $\mathrm{N} 1$ were found to pure-tone stimuli in BECTS group from $\mathrm{Fpz}, \mathrm{Fz}$ and $\mathrm{Cz}$ compare to control group. Regarding latencies of $\mathrm{N} 1$ and $\mathrm{N} 2 \mathrm{~b}$, only a slight delay was found for the BECTS group more pronounced in fronto-central electrodes positions (Fig. 1), but with no statistical significance. For pure-tone stimuli MMN in BECTS group was almost absent for all electrodes (Fig. 2).

\section{Consonant-vowel}

BECTS group revealed high amplitude of $N 2 b$ to deviant CV stimuli at $\mathrm{Cz}$ ( $p=0.075$, 1 -tailed) compared to control group
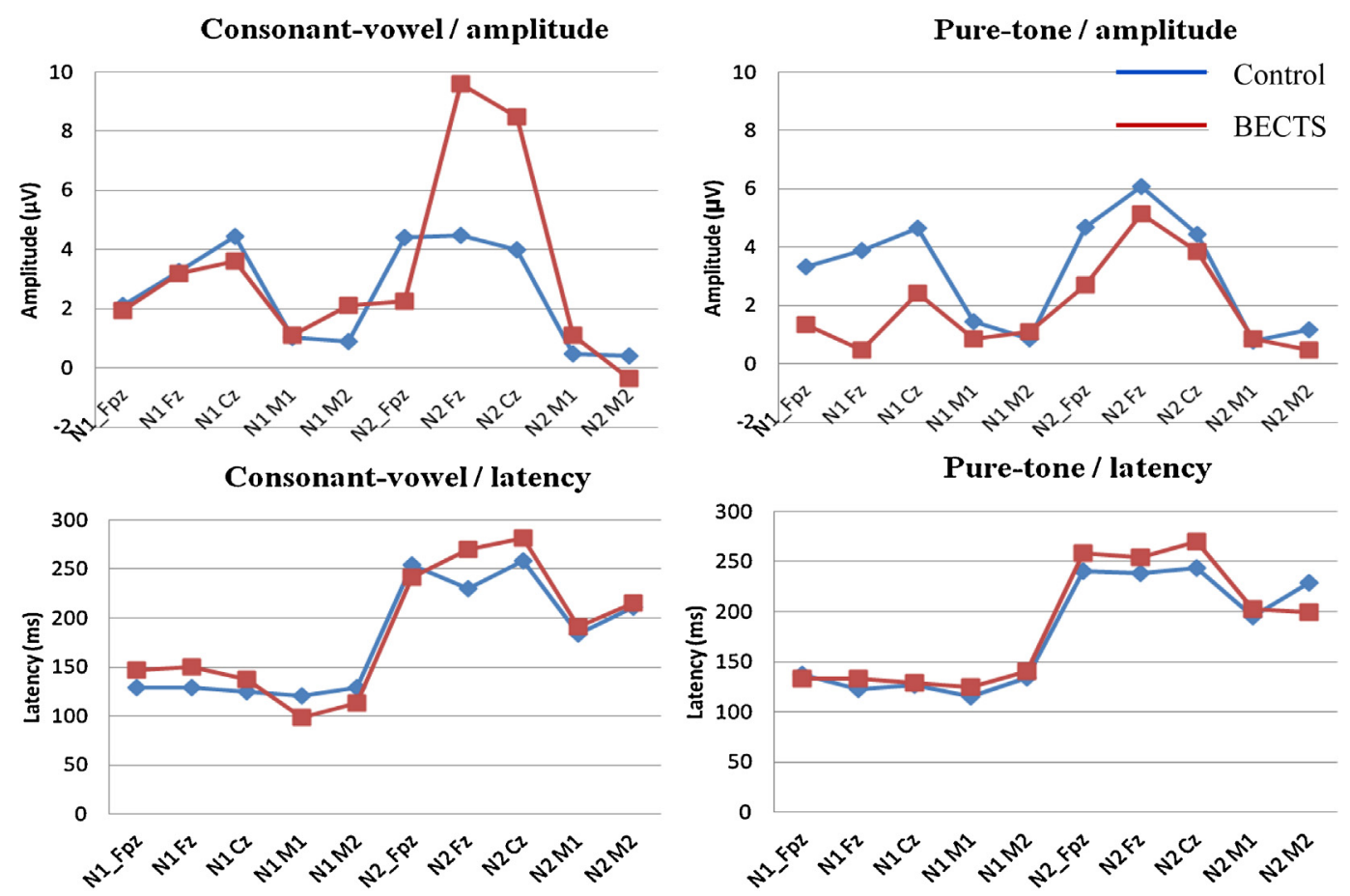

Figure 1 Distribution of components amplitude and latency mean values by electrode position of BECTS group (red) and control group (blue), for consonant-vowel and pure-tone paradigms. Note the enlargement of N2 amplitude in consonant-vowel paradigm from $\mathrm{Fz}$ and $\mathrm{Cz}$ in BECTS group. (For interpretation of the references to color in this figure legend, the reader is referred to the web version of this article.) 

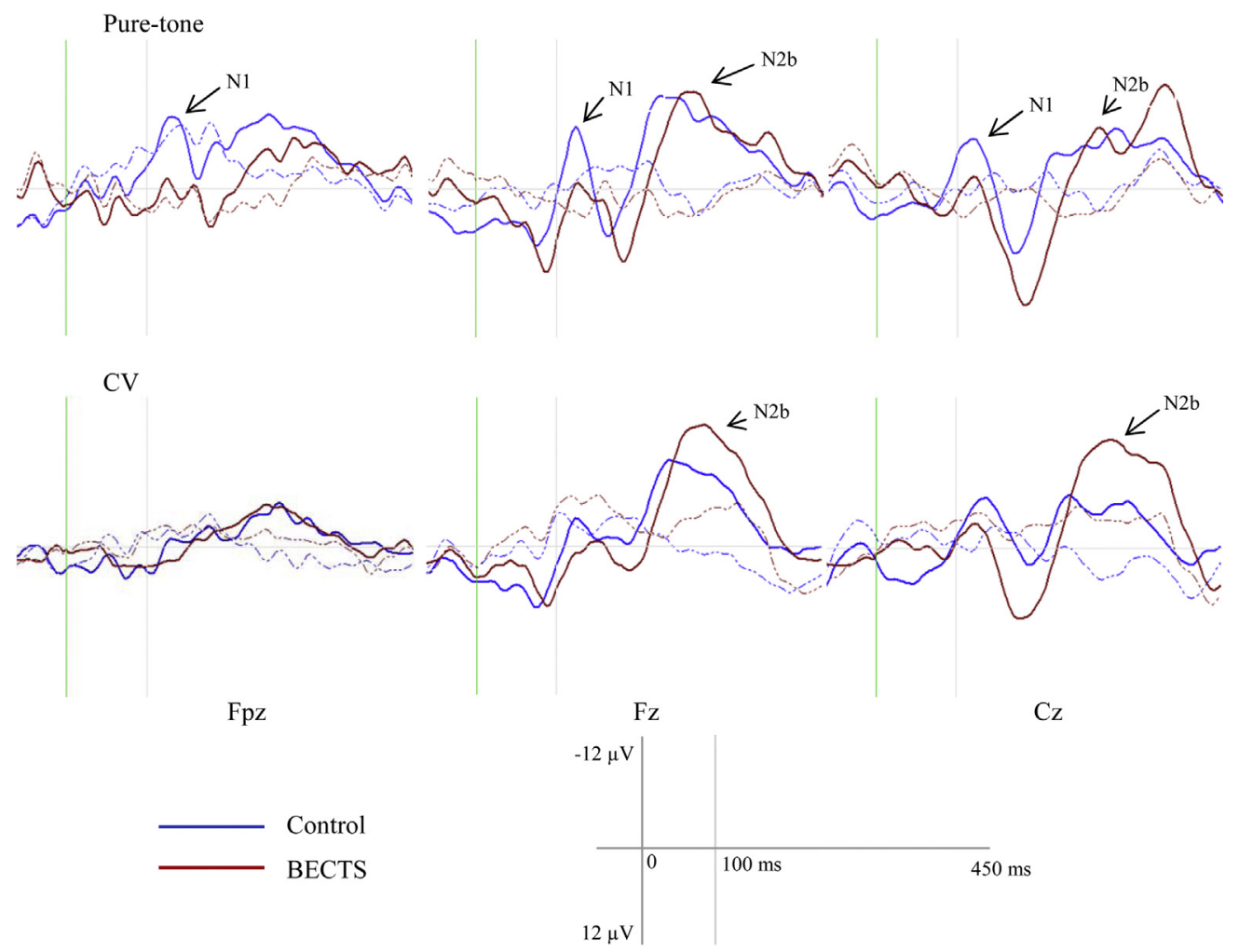

Figure 2 Grand average deviant waveforms for consonant-vowel (CV) and pure-tone paradigm for the BECTS group (red solid line) and the control group (blue solid line). Grand average MMN difference waveforms are represented by the dashed lines. (For interpretation of the references to color in this figure legend, the reader is referred to the web version of this article.)

(Figs. 1 and 2). In addition, mild reduced amplitudes of N1 were found to pure-tone stimuli in BECTS group from Fpz, $\mathrm{Fz}$ and $\mathrm{Cz}$, but with no statistical significance. Regarding latency, a slight but significant delay of N1 was found for the BECTS group from Fz ( $p=0.036,2$-tailed; Fig. 1$)$. No relevant differences were found between groups regarding $M M N$ waves for CV stimuli (Fig. 2).

\section{Discussion}

The findings in this study are consistent with literature, concerning increased excitability of cortical structures (Manganotti and Zanette, 2000; Skrandies and Dralle, 2004; Turkdogan et al., 2003; Liasis et al., 2006) and larger amplitudes in all frequency bands of the spontaneous EEG (Braga et al., 2000; Pan and Lüders, 2000) in BECTS. Although some subjects are on medication, only P300 seems to be affected by CBZ (Enoki et al., 1996). Our results illustrate that AERPs may detect and reveal increased cortical excitability in children with BECTS as reflected by N2b component in CV paradigm. However, the same amplitude enlargement is not seen with pure-tone stimuli, but slight reduced amplitude of $\mathrm{N} 1$ at $\mathrm{Fpz}, \mathrm{Fz}$, and $\mathrm{Cz}$ electrode positions, this is consistent with Boatman et al. (2008) study indicating integrity of the primary auditory cortex. Regarding $M M N$, results to speech stimuli seem consistent with the scarce literature. The amplitude reduction or absence of $M M N$ may indicate disruption of the evolution and maintenance of echoic memory traces (Liasis et al., 2006) possibly leading to impairments in speech recognition and consequent risk for academic difficulties (Boatman et al., 2008).

In agreement with other studies (Liasis et al., 2006; Rosburg et al., 2008), our results suggest a deficit in auditory novelty detection and orienting response, with a potential failure of inhibitory mechanisms, as reflected by decreased $\mathrm{N} 1$ and an enhancement of N2b component to speech stimuli. It seems that if the brain cannot orient a response by inhibiting irrelevant information, attention allocation processes are highly activated to compensate this. Furthermore, this is in keeping with recent findings showing the loss of inhibitory properties of pyramidal neurons is related to epileptogenesis (Yu et al., 2006; Dravet, 2012). Another explanation is that the enlargement of N2b to speech stimuli seen in BECTS group, share the same cortical generator as the spontaneous rolandic spikes.

These results provide new insights into altered brain processes underlying the discrimination and perception of speech and non-speech in the presence of rolandic epilepsy. Supporting our view that AERPs can provide a useful tool to detect and reliably reveal cortical excitability in children with typical BECTS that might be at risk for language deficits and school difficulties. However, the connection or possible interrelation between cortical excitability, medication and neuropsychological assessment still needs to be investigated and clarified in further studies with more participants.

\section{Conflicts of interest statement}

None of the authors has any conflict of interest to disclose. 


\section{References}

Bernardina, B.D., Sgró, V., Fejerman, N., 2005. In: Roger, J., Bureau, M., Dravet, Ch., Genton, P., Tassinari, C.A., Wolf, P. (Eds.), Epileptic Syndromes in Infancy, Childhood and Adolescence. , 4th edn. John Libbey Eurotext Ltd., Montrouge, France, pp. 203-225.

Boatman, D.F., Trescher, W.H., Smith, C., Ewen, J., Los, J., Wied, H.M., Gordon, B., Kossoff, E.H., Gao, Q., Vining, E.P., 2008. Cortical auditory dysfunction in benign rolandic epilepsy. Epilepsia 49 (6), 1018-1026.

Braga, N.I.O., Manzano, G.M., Nóbrega, J.A.M., 2000. Quantitative analysis of EEG background activity in patients with rolandic spikes. Clin. Neurophysiol. 111, 1643-1645.

Dravet, C., 2012. How Dravet syndrome became a model for studying childhood genetic epilepsies. Brain 135, 2309-2311.

Enoki, H., Sanada, S., Oka, E., Ohtahara, S., 1996. Effects of highdose antiepileptic drugs on event-related potentials in epileptic children. Epilepsy Res. 25, 59-64.

Ferri, R., del Gracco, S., Elia, M., Musumeci, S.A., 2000. Age-related changes of cortical excitability in subjects with sleep enhanced centrotemporal spikes: a somatosensory evoked potential study. Clin. Neurophysiol. 111, 591-599.

Henkin, Y., Kishon-Rabin, L., Gadoth, N., Pratt, H., 2002. Auditory event-related potentials during phonetic and semantic processing in children. Audiol. Neurootol. 7, 228-239.

Liasis, A., Bamiou, D.E., Boyd, S., Towell, A., 2006. Evidence for a neurophysiologic auditory deficit in children with benign epilepsy with centro-temporal spikes. J. Neural Transm. 113, 939-949.

Liasis, A., Towell, A., Alho, K., Boyd, S., 2001. Intracranial identification of an electric frontal-cortex response to auditory stimulus change: a case study. Cogn. Brain Res. 11, 227-233.

Liasis, A., Towell, A., Boyd, S., 1999. Intracranial auditory detection and discrimination potentials as substrates of echoic memory in children. Cogn. Brain Res. 7, 503-506.
Manganotti, P., Zanette, G., 2000. Contribution of motor cortex in generation of evoked spikes in patients with benign rolandic epilepsy. Clin. Neurophysiol. 111, 964-974.

Myatchin, I., Mennes, M., Wouters, H., Stiers, P., Lagae, L., 2009. Working memory in children with epilepsy: an event-related potentials study. Epilepsy Res. 86 (2), 183-190.

Näätänen, R., 1995. The mismatch negativity: a powerful tool for cognitive neuroscience. Ear Hear. 16, 6-18.

Nicolai, J., van der Linden, I., Arends, J.B., van Mil, S.G., Weber, J.W., Vles, J.S.H., Aldenkamp, A.P., 2007. EEG characteristics related to educational impairments in children with benign childhood epilepsy with centrotemporal spikes. Epilepsia 48 (11), 2093-2100.

Pan, A., Lüders, H.O., 2000. Epileptiform discharges in begnin focal epilepsy of childhood. Epileptic Disord. 2, 529-536.

Rosburg, T., Trautner, P., Ludowig, E., Helmstaedter, C., Bien, C.G., Elger, C.E., Boutros, N.N., 2008. Sensory gating in epilepsy effects of the lateralization of hippocampal sclerosis. Clin. Neurophysiol. 119, 1310-1319.

Skrandies, W., Dralle, D., 2004. Topography of spectral EEG and late VEP components in patients with benign rolandic epilepsy of childhood. J. Neural Transm. 111, 223-230.

Turkdogan, D., Onder, U., Akyuz, G., 2003. Visual and auditory event related potentials in epileptic children: a comparison with normal and abnormal MRI findings. Brain Dev. 25 (6), 396-400.

Wong, P.K.H., Gregory, D., Farrell, K., 1985. Comparison of spike topography in typical and atypical benign rolandic epilepsy of childhood. Electroencephalogr. Clin. Neurophysiol. 61,9 S47.

Yu, F.H., Mantegazza, M., Westenbroek, R.E., Robbins, C.A., Kalume, F., Burton, K.A., Spain, W.J., McKnight, G.S., Scheuer, T., Catterall, W.A., 2006. Reduced sodium current in GABAergic interneurons in a mouse model of severe myoclonic epilepsy in infancy. Nat. Neurosci. 9, 1142-1149. 